\title{
Level of Service Analysis for Metro Station with Transit Cooperative Research Program (TCRP) Manual: A Case Study- Shohada Station in Iran
}

\author{
Arash Azadpeyma ${ }^{1}$ Ehsan Kashi ${ }^{2}$
}

Received: 14 November 2018/Revised: 13 December 2018/Accepted: 14 December 2018/Published online: 26 December 2018

(C) The Author(s) 2018

\begin{abstract}
One of the main infrastructures in rail transportation is metro station. Obviously, analyzing and improving the capacity of the stations will ultimately lead to improved performance of the overall network. The capacity of metro station is the ability of the station and its associated spaces to create safety and comfort for the number of passengers expected to use the station. In this research, volume of passengers in the Shohada Square metro station has been used and simulated using VISSIM software. By the results of the simulation and regarding TCRP manual, six scenarios were analyzed in this research and different conditions were evaluated. Two main solutions for improving the performance of station were considered. It shows that the decision to remove the manual ticket purchase location will result in a $43 \%$ improvement in the performance of control space section and the approach to reducing the headway of trains from $240 \mathrm{~s}$ to $180 \mathrm{~s}$ will increase the amount of accessible space for each pedestrian in the platform to $35 \%$. The method presented in this study can be used to evaluate and analyze other metro stations and even other transportation network stations.
\end{abstract}

Keywords Capacity analysis - Level of service in station · Simulation of pedestrian movement - VISSIM - Transit Cooperative Research Program manual

Ehsan Kashi

e.kashi@iau-shahrood.ac.ir

1 Department of Civil Engineering, Damavand Branch, Islamic Azad University, Damavand, Iran

2 Department of Civil Engineering, Shahrood Branch, Islamic Azad University, Shahrood, Iran

Communicated by Xuesong Zhou.

\section{Introduction}

Due to the growing population of cities and increased intercity trips in many large cities, efficient public transport is essential. One of the best options for this problem is tunnels because of high density and limited space available on the ground. Demand for rail system is growing worldwide due to its proven benefits. This increase in passenger volumes will increase the demand for capacity of the system. Many rail lines are currently being used at near their maximum capacity, and actions need to be taken to respond to new demands [1].

Such actions include the construction of new infrastructure, the upgrading of existing infrastructures or the more efficient use of existing infrastructures. It is costly to build new infrastructures, and therefore, the optimal use of existing infrastructures is important. The issue of improving the use of the rail transport system can be directly linked to the capacity of infrastructure, transportation vehicles, timing of movement and the behavior of travelers [2].

One of the main infrastructures in the rail transport system is station. A station provides a means for passengers to purchase tickets and board trains. Analyzing and improving the capacity of the stations will ultimately improve the performance of the entire network. The capacity of a station is the ability of the station and its associated spaces to create safety and comfort for the number of passengers expected to use the station. Analysis of station capacity is done for these reasons: improving the comfort, satisfaction and safety of passengers, minimizing passenger congestion, increasing the flexibility in sudden rise of passengers' numbers and disturbances in train services and providing opportunities for increasing rail line 
activities in case of the need and sufficient support of rail services.

There are several definitions with regard to the capacity of the metro station in the literature. Person capacity is the number of people who can be relocated at a given time, which is discussed by Kittelson and associates [3]. The capacity of a station is equal to the maximum number of passengers traveling through the various facilities of the station. However, details have not been given in this definition, since it is difficult to express it. Therefore, the capacity of the station should be defined in practice.

Capacity analysis methods can be divided into two main categories: simulation and mathematical modeling. In general, mathematical models, often called analytical models, design the metro station system using mathematical formulas or algebraic expressions. But in this research, the topic of simulation will be discussed. Simulation means trying to find the answer to real problems in which a model will first be created as closely as possible to the real state, and the proposed solutions will be evaluated [4].

\section{Literature Review: Simulation of Station}

A condition of more number of users than the desirable level, which causes inconvenience to the users, is termed as congestion. In urban rail transport systems, the congestion needs to be monitored at the following locations: (a) inside trains; (b) at station; (c) in walkways or at platforms [5]. To assess the efficiency of any measure(s), it is important to objectively assess the congestion. The level of service (LOS) concept is widely used to define congestion in transport sector. Many factors' effects on the level of service have a significant impact on customer satisfaction. For the trains, the main factors include informing, station appearance, safety, cost, travel time, comfort and availability [6].

A metro station typically provides tickets vending and ticket validating systems. The station is divided into an unpaid zone connected to the street and a paid zone connected to the train platforms. The ticket barrier allows passengers with valid tickets to pass between these zones. This barrier may operate by staff or more typically with automated turnstiles or gates that open when a transit pass is scanned or detected. Access from the street to ticketing and the train platform is provided by stairs, concourses, escalators, elevators and tunnels. The station will be designed to minimize overcrowding and improve flow, sometimes by designating tunnels as one way. But there is a need to make adjustments to the station due to the increased demand for the system. One of the best ways for controlling any suggestion for improving the overall situation of station is simulation. Here are some new important articles about simulation of pedestrian flow in metro stations.
Gao and Jia in their research, after pointing out that a major rail transport service in the cities is the main way to reduce traffic congestion in cities, provide an integrated distribution of the passenger's flow based on the basic theory of passenger's flow analysis on the platform. Using a case study, they showed that their models were scientific and realistic, and this model can describe the dynamic variation of the distribution of pedestrian flows. Then authors look at the impact of the headway timing of the train movement on the planning of trains from the viewpoint of level of service and traffic safety [7].

In 2016, a study was conducted on the access and flow of passengers at Egypt's Cairo metro station. In this research, authors tried to evaluate the accessibility and convenience of passengers traveling by simulation method and using the manuals. The article states that this metro station has a desirable level of service in the area of purchase and control of tickets, and factors such as the lack of separation of pedestrians are the factors influencing this result. The researcher, in simulating of the station's architectural plan, concludes that it is advisable not to plan the space for buying tickets with sharp angles and that the space is designed to make the most dispersion of passengers in space to prevent overcrowding [8].

In 2017, Christopher and colleagues examined the effect of passenger's distribution along the platform to meet the objective of limiting train delay during stopping at the station. This paper evaluated the traffic performance of pedestrians and provides solutions based on informing passengers about the impact of their expected location on system performance. One of the solutions is to show the location of the passengers' departure from the train on the edge of the platform and the other to put a guide light that informs passengers the situation behind the door of trains. The researchers will present a model based on simulation under these conditions at a Western Paris subway station and assess the performance of the station in the application of these strategies [9].

In 2000, Hoogendoorn and Bovy, in their important research, state that having knowledge of pedestrian flow analysis is important in planning and designing railroad infrastructure such as stations. The lack of necessary knowledge about the behavior of pedestrians in different situations leads to more use of simulation and modeling. They introduced a new model called social force model. The governing equations in this model are capable of describing and analyzing the density of passengers in spaces [10].

Then, in 2004, according to the model, they designed the simulation method for station design and evaluated the flow of passengers according to parameters such as level of service, density, average travel time and delays in the gate. The research specifically evaluates the effect of the 
location of the gate and how it is used on the behavior of passengers by the simulation [11].

Galiza in 2016, after declaring that the use of the metro and rail transportation in cities has increased due to crowded streets and urban traffic and the metro stations have a high population density during peak traffic hours, points out that evaluation and design of station spaces are an important factor in maintaining the optimal level of service. Using micro-simulation with the ability to model pedestrians can be used to evaluate complex behaviors within these spaces. In this study, using the VISSIM software, the Melbourne Railway Station in Australia is simulated. This case study provided a good example for the potential implementation of micro-simulation models in the analysis of pedestrian circulation. It provides numerical results and graphical animations of activities that take place from the time a passenger enters until departing the station [12].

\section{Effective Parameters on Level of Service}

This research, using the TCRP and Highway Capacity Manual (HCM) 2016 regulations, will examine the main issues in the analysis and design of metro stations [13, 14]. It should be noted that the quality issues related to the level of service in different manuals are different from each other based on the initial assumptions and computational methods and how the information is collected, and for each region the criteria are different.

- Capacity of passengers The maximum number of people who can occupy or cross a service element is equivalent to the capacity of the passengers, and the unit is the number of individuals per minute or in terms of the number of people per minute per width. The maximum capacity indicates the maximum number of passengers, and design capacity indicates the maximum number of desirable passengers. Capacity of station can be increased with improving pedestrian's flow.

- Passengers speed The average passengers speed is usually expressed in meters per minute or seconds. In software, you can use a range of speeds of passengers rather than average speed. This is one of the main input parameters.

- Passenger flow rate The number of passengers passing through a point per unit time. The point can be any of the station's elements.

- Effective width or surface Part of the width or surface of a corridor or walkway that is commonly used by passengers. The surface occupied by physical obstacles and the peripheral areas adjacent to the edges of the platform, the walls and obstacles should not be considered in width or the effective area. The unit of this parameter is meter.

- Passenger traffic per unit of width Average passenger flow per unit of effective corridor width.

- Density of passengers The average number of people per area in a corridor or queue area.

- Passenger space per person The average area available for each pedestrian in a corridor or queue area, in unit of square meter per person. This space changes based on the activity of the passengers and the speed of their movement. It is necessary to consider the type and behavioral characteristics of travelers in this category.

LOS (level of service) is a useful tool for assessing the capacity and comfort of a pedestrian space. Limit values of LOS for passengers are based on the freedom to choose the speed for the pedestrian. Other considerations include the ability to cross the pedestrian traffic flow, walk in the opposite direction of a large pedestrian flow, the redirect without conflict with other pedestrians or change in pedestrian speed.

The level of service for pedestrian areas is defined by the available space, perceived comfort and safety and the ability to maneuver from one place to another. LOS ranges from $\mathrm{A}$ to $\mathrm{F}$, where $\mathrm{A}$ denotes conditions without limitations and $\mathrm{F}$ indicates an unfavorable condition in which pedestrian traffic is severely restricted. Pedestrian capacity (the maximum number of pedestrians who can move a point in a given time period) is shown by the amount LOS between $\mathrm{E}$ and F. However, usually the design of the station is on the basis of a favorable walking condition. The threshold for each LOS is defined in accordance with the specific medium available for each pedestrian. Pedestrian space can be used in planning and designing features such as platform size, stairway widths, corridor widths and more, in accordance with the level of service. LOS in the various components of the station, such as corridors, ticket control, stairs, elevators and platform, is stated in Chapter 10 of Transit Service and Quality of Service Manual, Third Edition, and the analysis is based on it [13].

\section{Shohada Square Metro Station}

This station is one of the stations on Line 4 of Tehran Metro. Tehran is one of the most populated cities in the world, and the performance and improvement of the city's metro performance will ultimately solve many of the city's problems, including traffic congestion and air pollution. Figure 1 shows the location of this metro station.

Data on the volume of passengers crossing at the station were obtained from Tehran Urban and Suburban Railway Operation Company. The organization provided data of the 


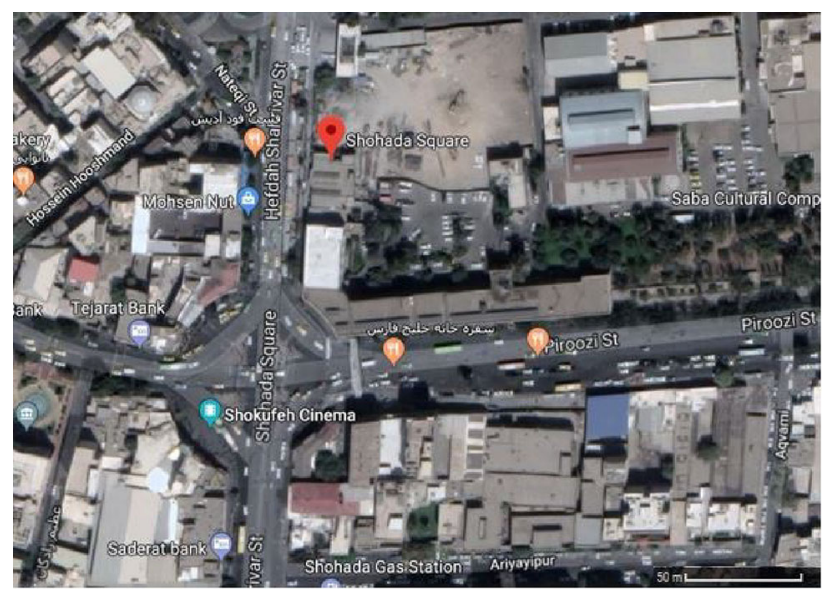

Fig. 1 Shohada Square metro station

busiest hour of a month and average number of passengers in a whole day in May, August and September 2017. These months are the best months in Iran for analysis of traffic. Table 1 shows the average number of passengers per hour in the month and the busiest hour of the month.

The remarkable point in this section is that these data are for all passengers entering the station from the main door and from trains. The author counted a number of passengers who used this station in morning peak hour of one normal day. According to this number, almost $80 \%$ of all passengers entered to the station. This percent was used for dividing the obtained number into entering and departing passengers. Different numbers have been used for the number of passengers in different scenarios, which we will continue to discuss.

\section{Modeling}

For the current research, the PTV VISSIM software will be used to simulate the behavior and status of the metro station spaces, and different scenarios will be created and compared.

VISSIM is a traffic simulation software developed by PTV in Karlsruhe, Germany, and is used in traffic engineering studies. The software was launched in 1992, and it is one of the most prominent softwares in the world. This software is a microscopic simulation tool for all vehicles and pedestrians and allows you to evaluate and analyze the complex operation of the passengers' movements in the design of transportation systems. The VISSIM software was first introduced in 1974 in Prof. Wiedemann's thesis for modeling moving cars in a single linear path. Further research was done to develop this software at the University of Karlsruhe, which focused more on the way of moving cars and modeling them. The first commercial version of this software was also used in 1994 to analyze the capacity of an intersection with timed traffic lights, after which the development of this software accelerated. Finally, in 2008, modeling pedestrian behavior was also added to the software based on the social force model of Helberg and Molnar research [15].

To simulate the underground station of the Shohada Square, it is necessary to plot the station plan first. The purpose of geometry is to define the space of the station in accordance with the existing and designed reality for this station. The station plan has four main levels, including entrance, ticket control, distribution and station platforms. Table 2 shows the elevation of levels and its dimensions.

Another key to simulating the station is to define the train path. However, in addition to defining the route of movement, the public transportation lines are also defined in the software so that it can be introduced headway of trains and train stop time at the station. Based on the available statistics an average time of train stop is $30 \mathrm{~s}$. Also, the headway of the trains will vary according to the timetable provided by Tehran Urban and Suburban Railway Operation Company in 2017 in different scenarios. According to researcher observations, each train wagon has a capacity of about thirty people, and as a result, each train has a capacity of about 180 people. It should be noted that this amount will only be used for a busy hour. In non-peak hours, trains have more empty capacity and therefore this number can be increased. Figure 2 shows 3D model of Shohada Square station in VISSIM simulation tool.

The pedestrian movement in the VISSIM software is based on the social force model [15]. The basis of this model is to model the primary motivation of passengers for moving in the same way as Newton's mechanical rules. Social, moral and physical forces will come to a complete force, which ultimately leads to the creation of a perfectly physically accelerated parameter. These forces arise from the will of the passengers to reach the destination and the impact of other passengers and obstacles. This model has been developed by the PTV group and has been used after adequate validation. In the first step, the macroscopic parameters were matched with experimental data by the researchers of this group. Then it was ensured that the microscopic effects, such as the formation of a queue and the crossing of the passengers together, were achieved in accordance with the facts. For further reading, we can refer to the guide in the software (section of the pedestrian walkway simulation) and the published article.

Also, in this section, after determining the volume of passengers entering the station, the speed of their movement should also be determined. In order to get as close as possible to the reality of the standard, people were divided into six categories at different speeds. Table 3 shows these six categories. Passengers' routes were also defined in the 
Table 1 Data obtained from Tehran Urban and Suburban Railway Operation Company

\begin{tabular}{lll}
\hline Busiest hour of month & Average number of pedestrians in hour \\
\cline { 1 - 2 } Hour & Number of pedestrians & \\
\hline 7-8 AM of 9th May & 3774 & 1253 \\
8-9 AM of 22nd September & 2995 & 1181 \\
7-8 AM of 22nd October & 3474 & 1204 \\
\hline
\end{tabular}

Table 2 Elevation and dimension of station spaces

\begin{tabular}{llc}
\hline Space name & Elevation from sea level $(\mathrm{m})$ & Dimension $\left(\mathrm{m}^{2}\right)$ \\
\hline entrance & 1175.6 & $6 \times 2.5$ \\
Ticket control and purchasing & 1163.7 & $28.5 \times 14$ \\
Distribution area & 1159.25 & $15 \times 14$ \\
Platform & 1154.25 & $140 \times 14$ \\
\hline
\end{tabular}

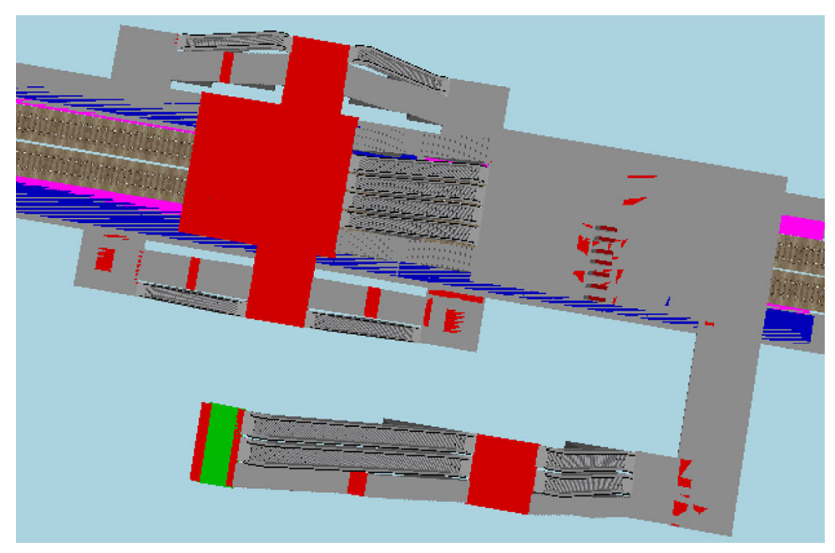

Fig. 2 3D model of Shohada Square station in VISSIM program

software so that the passengers were properly moved through the station.

The waiting time for the purchase of a ticket was considered a normal distribution with an average of $10 \mathrm{~s}$ and a standard deviation of 0.5. Also, waiting time for crossing the gates in the station also has a normal distribution with an average time of $4 \mathrm{~s}$ and standard deviation 0.3. It should be noted that in order to reach this number, the station was evaluated for $30 \mathrm{~min}$ and then the distribution was

Table 3 Pedestrians movement speed in station

\begin{tabular}{lllc}
\hline & Gender & $\begin{array}{l}\text { Walking speed }(\mathrm{m} / \\
\text { s) }\end{array}$ & $\begin{array}{l}\text { Relative } \\
\text { flow }\end{array}$ \\
\hline 1 & Male & 0.8 & 16 \\
2 & Male & 1.32 & 6 \\
3 & Male & 1.53 & 45 \\
4 & Female & 0.8 & 9 \\
5 & Female & 1.32 & 4 \\
6 & Female & 1.53 & 20 \\
\hline
\end{tabular}

appropriately selected on the data. After simulating the station, the researcher presents six scenarios for comparing different conditions and improving station status.

\subsection{Scenario 1}

In the first step, it is necessary to analyze and evaluate the current status of the station under normal conditions and under the average daily data of the station. In this scenario, the station's status is simulated like its reality. The main inputs of this scenario are shown in Table 4.

After importing these inputs into the model created in the software and performing the simulation process, the necessary outputs were extracted. According to this simulation, the available space for each passenger in the ticket control section and platform is 35.87 sq. $\mathrm{m}$ and 2.8 sq. $\mathrm{m}$, and the average speed of pedestrians in each of these sections is $0.69 \mathrm{~m} / \mathrm{s}$ and $0.02 \mathrm{~m} / \mathrm{s}$ and LOS is A.

In this part of the research, in order to evaluate the validity of the simulated model, the author takes some photographs from different sections of station during normal traffic hours (non-peak), and this photograph was compared with images taken from software environment. These photographs are shown in Figs. 3 and 4.

Table 5 shows the difference between the number of passengers in the simulated station spaces in the software and the actual space of the station at non-peak traffic hours.

Table 4 Scenario 1 inputs

\begin{tabular}{ll}
\hline Number of entrance pedestrians to station in $1 \mathrm{~h}$ & 1002 person \\
Number of leaving pedestrians from train in $1 \mathrm{~h}$ & 250 person \\
Trains capacity in each train & 720 person \\
Train movement headway in station & $360 \mathrm{~s}$
\end{tabular}




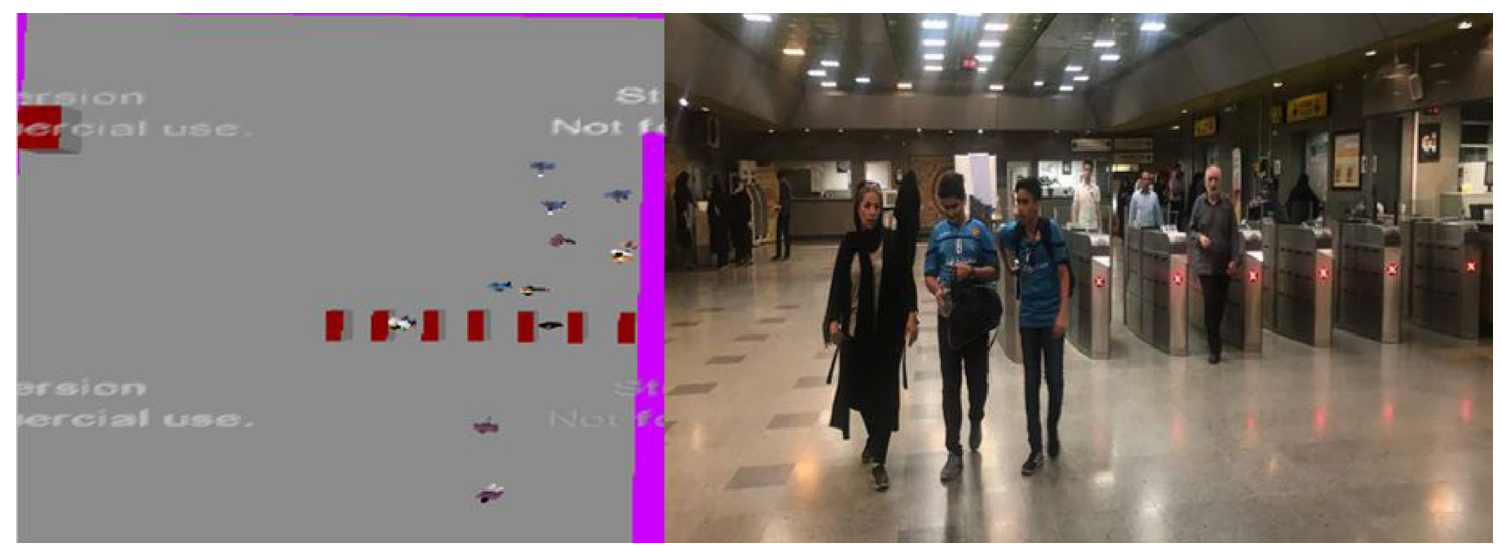

Fig. 3 Validation of ticket control section in Shohada Square station

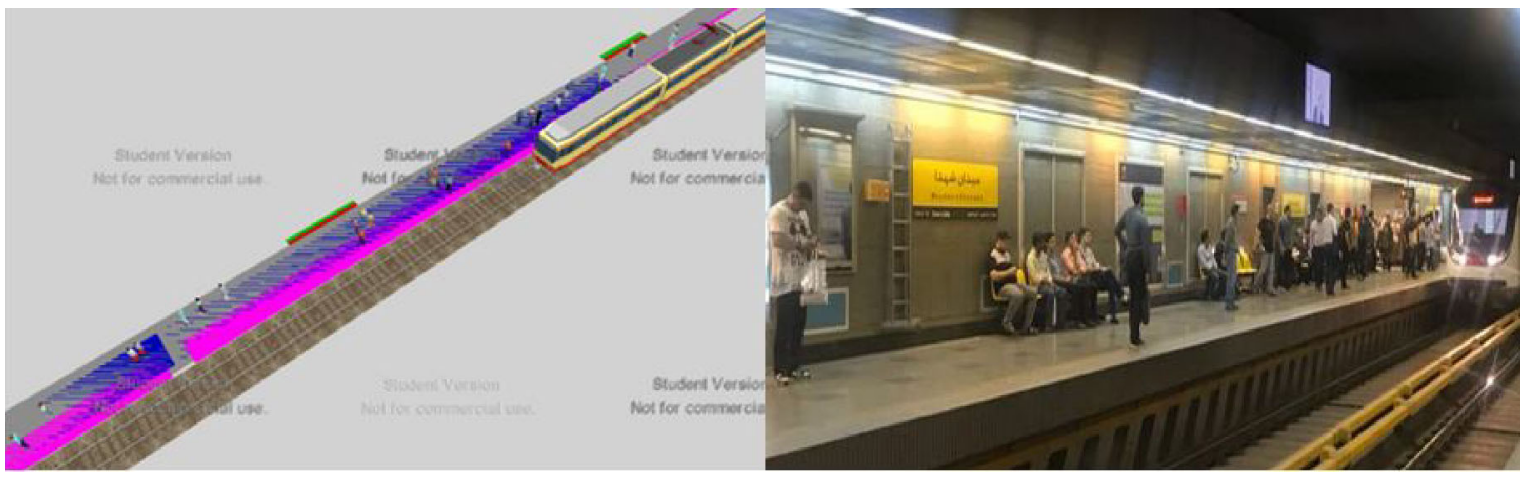

Fig. 4 Validation of platform in Shohada Square station

Table 5 Deviation percent of pedestrian numbers in Shohada Square station

\begin{tabular}{llll}
\hline Space name & \multicolumn{2}{l}{ Number of pedestrians } & Deviation percent (\%) \\
\cline { 2 - 3 } & Reality & Software & \\
\hline Ticket control and purchasing & 12 & 12 & 0 \\
Platform & 23 & 25 & 8.6 \\
\hline
\end{tabular}

In the absence of sufficient information to simulate passengers, according to the FHWA 2004, 10\% deviation of the passage volume on the platform and $5 \%$ of the deviation in the other station spaces are acceptable for simulation [16]. The control between reality and output of model on the software shows that the software outputs are accurate enough and then it can be used to analyze other scenarios.

\subsection{Scenario 2}

In this section, the conditions at the peak hours of the day will be examined. Trains' headway in Tehran metro is reduced to $240 \mathrm{~s}$ to improve the performance of subway lines at peak hours' times by Tehran Urban and Suburban Railway Operation Company.
According to the analysis, the amount of space available for passengers in this situation is reduced compared to the first one, but according to the manual, the overall level of service of the station is still in the best condition (LOS of A). The amount of available space for each pedestrian in these conditions in the ticket control section and the platform is 11.82 sq. $\mathrm{m}$ and 1.5 sq. $\mathrm{m}$, and the speed of pedestrians in these spaces is $0.65 \mathrm{~m} / \mathrm{s}$ and $0.04 \mathrm{~m} / \mathrm{s}$. The reason for LOS A can be related to the modernization of the Shohada Square metro station and the proper design of the station and the appropriateness of train headway.

\subsection{Scenario 3}

One of the ways to improve the status of the station at peak times is to remove the ticket purchase location and the location of the resulting queue. It is suggested that the 
tickets used in Tehran Metro are purely electronic and can be purchased by other methods such as the Internet or ATM.

Recently, machines have been installed in the metro stations of Tehran, which can be used to charge electronic tickets without the need for an operator. Using many devices in this space is possible due to the proper dimensions of this section of the station, and this will prevent the occurrence of a queuing due to the purchase of tickets manually.

In this case, input values are the same as in Scenario 2, and only the LOS of the ticket control service improves. In the event of this modification, the formation of a queue will be prevented, and the available space for passengers will change from 11.82 sq. $\mathrm{m}$ per person to 17.37 sq. m per passenger, which means $46 \%$ improvement (Table 6).

\subsection{Scenario 4}

A solution that can be used to improve the overall network status is the reduction in trains' headway. This solution will cause more passengers to travel and reduce time delay. In this section, the researcher's suggestion is to reduce the headway time to $180 \mathrm{~s}$, and supplying this time is more accessible and cost-effective according to the current situation.

This scenario will increase the available space for pedestrians on the platform. If this change is made, the available space for pedestrians in the platform will increase from 1.5 sq. m per person to 1.77 sq. m, which means an improvement of $15 \%$ in this index. It should be noted that this form of correction will not only improve the indicators related to the station, but also by reducing the delay in all stations and preventing the accumulation of passengers in platforms and waiting spaces, this modification will improve the overall performance of the network and will increase the satisfaction of the passengers.

\subsection{Scenario 5}

After reviewing the present status, it is necessary to consider the increasing number of passengers over time suitable. In this regard, we estimate the population growth over the past 10 years. According to a World Bank report

Table 6 Scenario 2 inputs

\begin{tabular}{ll}
\hline Number of entrance pedestrians to station in $1 \mathrm{~h}$ & 3020 person \\
Number of leaving pedestrians from train in $1 \mathrm{~h}$ & 754 person \\
Trains' capacity in each train & 180 person \\
Train movement headway in station & $240 \mathrm{~s}$ \\
\hline
\end{tabular}

released in 2016, the rate of population growth in Iran is $1.2 \%$, but the assumption of the equalization of population growth in Tehran with its rate in the country cannot be correct.

Tehran, as the capital of country, is an immigrant city. According to the statistics provided by the Iranian Statistics Center in the year 2016, Tehran's population growth in the 5 -year period was 1.95 , compared with the country's growth rate of that year (1.24) Has a ratio of 1.5. Therefore, the researcher will apply the World Bank's announced growth rate to a coefficient confidence of 1.5. In this case, the number of passengers at peak hours in the next 25 years will be calculated according to the formula below.

$F=P(1+i)^{n}$

where $F$ is number of passengers in $n$ years later, $P$ is the number of passengers at this time, $i$ is the population growth rate, and $n$ is the number of years.

$F=3774(1+(0.012 * 1.5))^{25} \approx 5895$

According to this calculation, the number of passengers at the station will be 5895 at the peak hour 25 years later, and we will maintain the existing headway.

The simulation carried out in order to consider the increase in population indicates the performance of the station spaces in relatively suitable conditions. In this situation, the available space for each pedestrian in the ticket control section and platform is 2.83 and 0.61 sq. $\mathrm{m}$, and the average speed of pedestrians is $0.53 \mathrm{~m} / \mathrm{s}$ and $0.03 \mathrm{~m} / \mathrm{s}$.

The LOS of ticket control section in this scenario is B, and it can be considered acceptable. But the LOS of the platform is D and it is close to the failure limitation, and in a particular situation where the capacity of the trains reaches its maximum or the number of passengers entering the platform will be more than this amount, this situation is not acceptable.

\subsection{Scenario 6}

In this part, the amount of population increase at the station from the last scenario is considered, and to improve the performance of the station, trains' headway reduces to $180 \mathrm{~s}$ and the place for manually purchasing tickets will be eliminated.

By eliminating the ticket purchase location, the LOS of ticket control section will improve. By this modification, the formation of the queue will be prevented, and the available space for passengers will be changed from 2.83 sq. $\mathrm{m}$ per person to 5.23 sq. $\mathrm{m}$ per passenger. This increase in available space will make it possible to keep LOS above failure limitation for a number of years in ticket control section. 
Also, this scenario will increase the available space for pedestrians on the platform by reducing the trains' headway. If this change is made, the available space for pedestrians in the platform will increase from 0.61 sq. $\mathrm{m}$ per person to 0.88 sq. $\mathrm{m}$, which means $44 \%$ improvement in the index, and the LOS increases from D to C.

\section{Results}

After simulating under different scenarios, we will compare the results. First, the amount of available space for each person will be compared based on square meters, under different scenarios in the critical areas of ticket control and platform. Figure 5 and 6 show this parameter.

By looking at these graphs, you can easily compare the percentage of changes in different scenarios and see that the most critical scenario is 5. The decreasing of amount of available space for passengers in the second scenario is quite evident from the first scenario, and it can be noted that the increase in the number of passengers entering the station does not linearly reduce the capacity of the station spaces and by passing a certain amount the intensity of this reduction will be more. It is better to avoid getting close to this certain density of passengers by providing the solutions presented in this research and other solutions.

In this simulation, the average travel time of passengers from the moment of arrival in the station was taken up to the moment of leaving station, and it is shown in Fig. 7.

Under scenario 5, all examined parameters include the available space for pedestrians in the platforms and ticket control section, as well as the travel time, will be critical.

Among the strategies for improving the station space by solution of removing the place of manual purchase of tickets and solution of reducing the time trains headway, the first solution has a greater impact on travel time.

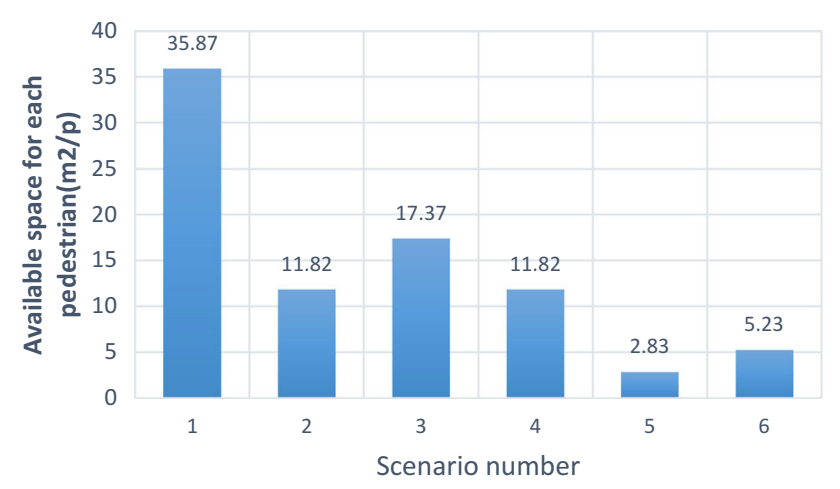

Fig. 5 Pedestrian space in ticket control section under different scenarios

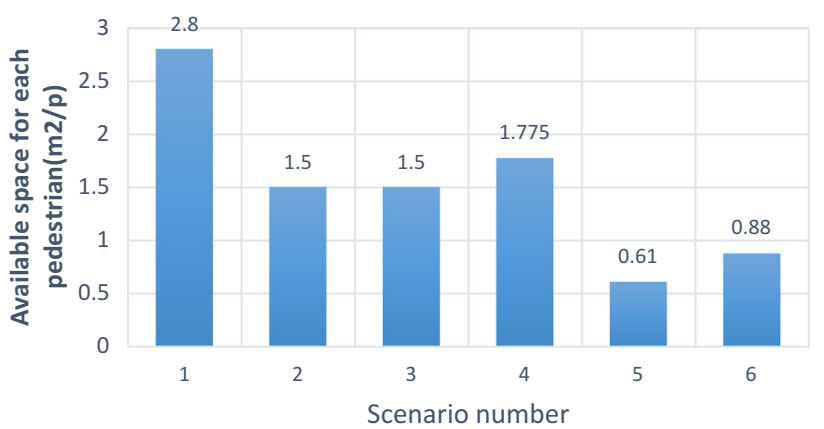

Fig. 6 Pedestrian space in platform under different scenarios

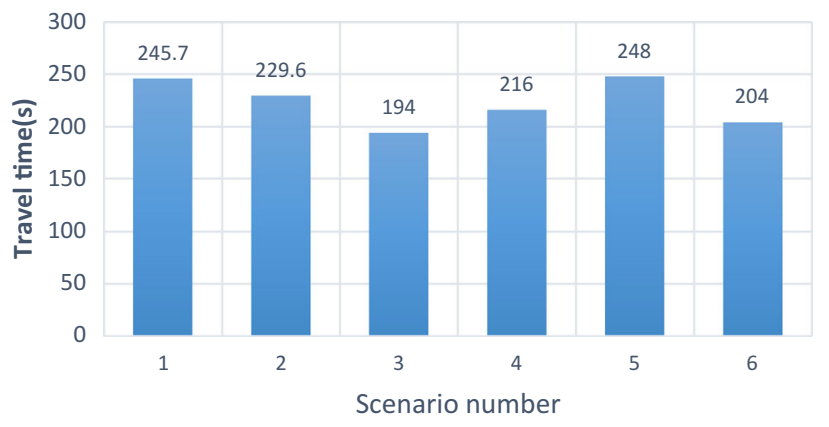

Fig. 7 Travel time in each scenario

According to this figure, the station's density will increase over the next 25 years and regard to population growth rate of $1.2 \%$, about $75 \%$ at ticket control location, and the LOS of the station will decrease over the years.

\section{Summary and Conclusion}

In this study, in order to determine the effect of the two solutions on the capacity of the station, simulation method was used with VISSIM software. The Shohada Square metro station was modeled on the software, and then different scenarios were evaluated. The authors cannot have optimization for designing the station because of constant dimensions of this special case. This article examines two main ideas in different conditions (different volume of passengers in station) to improve pedestrians flow and LOS. Here is the main conclusion of this simulation.

- In the peak hours of traffic, despite the increasing number of passengers, due to the decrease in the train headway that was planned by the Tehran Urban and Suburban Railway Operation Company and the modernization of the metro station, the LOS is still A.

- The decision to remove the manual ticket purchase location will result in a $43 \%$ improvement in the performance of this space, due to the lack of queues in the area and the easy crossing of passengers. 
- The approach to reducing the headway of trains will increase the amount of accessible space for each pedestrian in the platform to $35 \%$. This solution also facilitates the flow of pedestrians at the station and reduces the travel time.

- In this study, according to the World Bank's declared growth rate, the number of passengers was estimated in the next 25 years and was analyzed in the fifth scenario. This increase in the volume of passengers will reduce the LOS of the various spaces of the station, and in particular, the escalator at the station will be degraded. The solution to this event is to provide parallel transportation systems. It is also possible to change some of the station's characteristics.

- Both proposed solutions were used to improve the station's performance under peak traffic conditions for the fifth scenario. The extent of the impact of these two strategies, if applied to the fifth scenario, is more visible. It can be said that planners should use these two solutions to prevent excessive traffic congestion on the station platform and long queues to buy tickets manually.

It should be noted that evaluating all the factors involved in transportation systems is very difficult and sometimes impossible. This research is not an exception to this, but it is better to do more research by other researchers and evaluate some parameters such as the effect of the pedestrians' speed, the lack of use of ticket control gates if alternative solutions are offered, and so on. It is also possible to compare the existing rules in this area and validate the results of this simulation in terms of the behavior of pedestrians in different countries.

Open Access This article is distributed under the terms of the Creative Commons Attribution 4.0 International License (http://crea tivecommons.org/licenses/by/4.0/), which permits unrestricted use, distribution, and reproduction in any medium, provided you give appropriate credit to the original author(s) and the source, provide a link to the Creative Commons license, and indicate if changes were made.

\section{References}

1. Perkins A, Ryan B, Siebers P-O (2015) Modelling and simulation of rail passengers to evaluate methods to reduce dwell times. In: 14th international conference on modelling and applied simulation, MAS 2015, 21-23 September 2015, Bergeggi, Italy

2. Lai YC, Barkan CP (2011) Comprehensive decision support framework for strategic railway capacity planning. J Transp Eng 137(10):738-749

3. Kittelson \& Associates, United States. Federal Transit Administration, Transit Cooperative Research Program, \& Transit Development Corporation (2003) Transit capacity and quality of service manual (No. 100). Transportation Research Board

4. Wilson N, Fourie CJ, Delmistro R (2016) Mathematical and simulation techniques for modelling urban train networks. S Afr J Ind Eng 27(2):109-119

5. Sarkar PK, Jain AK (2017) Defining and assessing congestion inside metro trains and at station: case study of Delhi Metro, India. Int J Traffic Transp Eng 7(1):93-107

6. Saputra AD (2010) Analysis of train passenger responses on provided service: case study: PT. Kereta Api Indonesia and Statens Jarnvagar (SJ) AB, Sweden

7. Gao L, Jia L (2016) Modeling and simulation of passenger flow distribution in urban rail transit hub platform. Preprints, 2016090085. https://doi.org/10.20944/preprints201609.0085.v1

8. Eldakdoky S (2016) A study of equitable accessibility and passengers flow in future stations of Cairo Metro. J Eng Sci 44(4):403-417

9. Christoforou Z, Collet PA, Kabalan B, Leurent F, De Feraudy A, Ali A, Li Y (2017) Influencing longitudinal passenger distribution on railway platforms to shorten and regularize train dwell times. Transp Res Rec J Transp Res Board 2648:117-125

10. Hoogendoorn S, Bovy P (2000) Gas-kinetic modeling and simulation of pedestrian flows. Transp Res Rec J Transp Res Board 1710:28-36

11. Hoogendoorn S, Hauser M, Rodrigues N (2004) Applying microscopic pedestrian flow simulation to railway station design evaluation in Lisbon, Portugal. Transp Res Rec J Transp Res Board 1878:83-94

12. Galiza RJ, Kim I, Ferreira L, Laufer J (2009) Modelling pedestrian circulation in rail transit stations using micro-simulation. In Proceedings of the 32nd Australasian Transport Research Forum (ATRF)

13. KFH Group (2013) National academies of sciences, engineering, and medicine. Transit capacity and quality of service manual, 3rd edn. The National Academies Press, Washington. https://doi.org/ $10.17226 / 24766$

14. Transportation Research Board National Research Council (2016) Highway capacity manual. TRB Business Office

15. Helbing D, Molnár P (1995) Social force model for pedestrian dynamics. Phys Rev E 51:4282

16. FHWA (2004) Traffic analysis toolbox volume III: guidelines for applying traffic microsimulation software. FHWA-HRT-04-040 